\title{
Circumdatin H, a New Inhibitor of Mitochondrial NADH Oxidase, from Aspergillus ochraceus
}

\author{
M. Pilar López-Gresa, M. Carmen González, Jaime Primo, Pilar Moya, \\ Vanessa Romero, Ernesto Estornell
}

Received: March 24, 2005 / Accepted: June 1, 2005

(C) Japan Antibiotics Research Association

\begin{abstract}
Circumdatin H (1), a new alkaloid from the culture broth of Aspergillus ochraceus, has been isolated, together with a known circumdatin, circumdatin E (2) and other known compounds: flavacol (3) and stephacidin A (4). The structure of $\mathbf{1}$ was established on the basis of chemical and spectral evidence. All of these alkaloids showed biological activity as inhibitors of the mammalian mitochondrial respiratory chain.
\end{abstract}

Keywords Aspergillus ochraceus, alkaloids, benzodiazepine, circumdatin, flavacol, stephacidin A, mitochondrial respiratory chain inhibitors

\section{Introduction}

Many natural products from Aspergillus ochraceus extracts show very interesting biological activities, such as antitumor activity [1 3] (e.g. avrainvillamide and stephacidin A and B) and antifungal [4], insecticide [5] and antibiotic [6] activities. Recently, a new group of benzodiazepines, circumdatins $A \sim G$, has been isolated from this fungus [7 9]. This group is considered a good chemotaxonomic marker for A. ochraceus fungus (Aspergillus subgenus Circumdati, section Circumdati, formerly the $A$. ochraceus group).

In the search for biologically active metabolites, an extract of A. ochraceus culture broth was studied. In this manuscript the isolation from this extract of a new

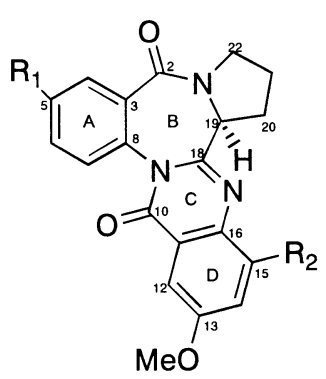

Circumdatin $\mathrm{H}$ (1) $\mathrm{R}_{1}=\mathrm{H}, \mathrm{R}_{2}=\mathrm{H}$

Circumdatin E (2) $\mathrm{R}_{1}=\mathrm{H}, \mathrm{R}_{2}=\mathrm{OH}$

Circumdatin D (5) $\mathrm{R}_{1}=\mathrm{OMe}, \mathrm{R}_{2}=\mathrm{OH}$

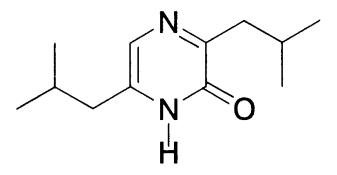

Flavacol (3)

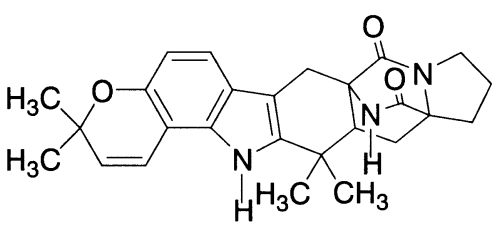

Stephacidin A (4)
M. P. López-Gresa (Corresponding author), M. C. González, J. Primo, P. Moya: Centro de Ecología Química Agrícola, Universidad Politécnica de Valencia, Campus de Vera, Edificio 9B, Laboratorio 111, 46022 Valencia, Spain, E-mail: mplopez@ceqa.upv.es
V. Romero, E. Estornell: Departament de Bioquímica i Biologia Molecular, Facultat de Farmàcia, Universitat de València, Avgda Vicent Andrés Estellés s/n, 46100 Burjassot (València), Spain 
circumdatin (1), with three other known alkaloids $(\mathbf{2} \sim \mathbf{4})[2$, $8,10,11]$, is reported. All of these alkaloids were assayed as inhibitors of integrated electron transfer chain, due to their structural analogies with well-known inhibitors of the respiratory chain $[12,13]$.

\section{Materials and Methods/Experimental}

\section{General Experimental Procedures}

Optical rotation was measured with a Jasco P-1030 polarimeter. IR spectra were obtained with a Nicolet $710 \mathrm{FT}$ spectrophotometer. UV spectrum was obtained using a Shimadzu UV-210PC spectrophotometer. Mass spectra were performed with a VG Auto Spec Fisons spectrometer. ${ }^{1} \mathrm{H},{ }^{13} \mathrm{C}$ and COSY H-H NMR spectra were recorded on a Bruker $300 \mathrm{MHz}$. Multiplicities of ${ }^{13} \mathrm{C}$ NMR were determined by DEPT experiments. For the HSQC and HMBC NMR experiments a Bruker 600 spectrometer was used. TLC was run on Silica gel $\mathrm{F}_{254}$ precoated plates (Merck 5554) and spots were detected by UV light. Isolation of alkaloids 1 4 was carried by a Waters HPLC system, with a 600 pump and a 2996 Photodiode Array Detector.

\section{Taxonomic of Producers}

The fungus was isolated from infected soil in our laboratory and was classified by the Centralbureau voor Schimmelcultures (CBS, Utrecht, The Netherlands) as Aspergillus ochraceus Wilhelm. A sample of this strain is deposited in the "Cátedra de Ecología Química Agrícola" of the Universidad Politécnica de Valencia. It is coded as HG10 and kept in agar slants with potato dextrose agar (PDA) as culture medium.

\section{Fermentation}

The strain was seeded in Petri dishes with PDA culture medium and incubated for 7 days at $28^{\circ} \mathrm{C}$. Then, a solution of Tween $80(0.05 \%)$ in sterile distilled water was used to obtain a suspension containing $c a \cdot 10^{6}$ conidia $/ \mathrm{ml}$. This suspension $(100 \mathrm{ml})$ was added to a 5-liter Erlenmeyer flask with 1 liter of antibiotic test broth (composition: yeast extract, $2.0 \mathrm{~g}$; bacto peptone, $3.0 \mathrm{~g}$; glucose, $2.0 \mathrm{~g}$; sucrose, $30.0 \mathrm{~g}$; corn steep, $5.0 \mathrm{~g} ; \mathrm{NaNO}_{3}, 2.0 \mathrm{~g} ; \mathrm{K}_{2} \mathrm{HPO}_{4} \cdot 3 \mathrm{H}_{2} \mathrm{O}$, $1.0 \mathrm{~g} ; \mathrm{MgSO}_{4} \cdot 7 \mathrm{H}_{2} \mathrm{O}, 0.5 \mathrm{~g} ; \mathrm{KCl}, 0.2 \mathrm{~g} ; \mathrm{FeSO}_{4} \cdot 7 \mathrm{H}_{2} \mathrm{O}$, $0.01 \mathrm{~g}$; distilled water, $1000 \mathrm{ml} ; \mathrm{pH} 7$ ) and was incubated for 22 days, in the dark, with shaking (200 rpm), at $25^{\circ} \mathrm{C}$.

\section{Isolation/Purification}

After incubation, the mycelia were removed from the culture broth by filtration. Then the broth (30 liters) was partially evaporated in vacuum to 1 liter and was extracted with $\mathrm{CH}_{2} \mathrm{Cl}_{2} /$ EtOAc $1: 1$ ( $3 \times 1$ liter). The $\mathrm{CH}_{2} \mathrm{Cl}_{2} /$ EtOAc $1: 1$ extract was dried under reduced pressure to obtain a brown solid $(5.2 \mathrm{~g})$. This resulting organic extract was partitioned by flash column chromatography on Silica gel (1: 100, w/w) using stepwise gradient from $\mathrm{CH}_{2} \mathrm{Cl}_{2}$ to $\mathrm{MeOH}\left(\mathrm{CH}_{2} \mathrm{Cl}_{2} ; \mathrm{CH}_{2} \mathrm{Cl}_{2} /\right.$ EtOAc $70 / 30 ; \mathrm{CH}_{2} \mathrm{Cl}_{2} /$ EtOAc 50/50; $\mathrm{CH}_{2} \mathrm{Cl}_{2} /$ EtOAc 20/80; EtOAc; EtOAc/MeOH 96/4; EtOAc/MeOH 8/2; MeOH). 1 liter of each mobile phase was eluted and eight fractions were collected.

The fourth fraction $(130 \mathrm{mg})$ was subjected to flash column chromatography on Silica gel $(1: 100$, w/w) using as mobile phase $\mathrm{CH}_{2} \mathrm{Cl}_{2} / \mathrm{MeOH} 98: 2$. This mixture was eluted and collected in aliquots of $3 \mathrm{ml}$, which were pooled in ten subfractions according to their similarity by TLC. Subfractions 4 (SF-4) and 5 (SF-5) were analyzed by HPLC. Semipreparative HPLC of SF-4 (18.3 mg) was performed using the following conditions: Spherisorb ODS2 C18 column, $5 \mu \mathrm{m}(25.0 \times 0.7 \mathrm{~cm})$; mobile phase $\mathrm{MeOH} / \mathrm{H}_{2} \mathrm{O}(70 / 30, \mathrm{v} / \mathrm{v})$; flow, $1 \mathrm{ml} /$ minute; detection by Photodiode Array. Two pure products were obtained from SF-4: (1) [retention time $(\mathrm{Rt})=19.89$ minutes; $1.2 \mathrm{mg}$ ] and (2) $[\mathrm{Rt}=11.45$ minutes; $2.5 \mathrm{mg}]$. Semipreparative HPLC of SF-5 (5.8 mg) was performed using the following conditions: Spherisorb ODS2 C18 column, $5 \mu \mathrm{m}$ $(25.0 \times 0.7 \mathrm{~cm})$; mobile phase $\mathrm{MeOH} / \mathrm{H}_{2} \mathrm{O}(70 / 30, \mathrm{v} / \mathrm{v})$; flow, $1 \mathrm{ml} / \mathrm{minute}$; detection by Photodiode Array. One pure product was obtained from SF-5: (3) $[\mathrm{Rt}=14.53$ minutes; $5.0 \mathrm{mg}]$.

The fifth initial fraction (132 mg) was subjected to flash column chromatography on Silica gel $(1: 100$, w/w) using as mobile phase $\mathrm{CH}_{2} \mathrm{Cl}_{2} / \mathrm{MeOH} 96: 4$. This mixture was eluted and collected in aliquots of $3 \mathrm{ml}$, which were pooled in eleven subfractions according to their similarity by TLC. Subfraction 6 (SF-6) was analyzed by HPLC. Semipreparative HPLC of SF-6 (21.2 mg) was performed using the following conditions: Spherisorb ODS2 C18 column, $5 \mu \mathrm{m}(25.0 \times 0.7 \mathrm{~cm})$; mobile phase $\mathrm{MeOH} / \mathrm{H}_{2} \mathrm{O}$ (70/30, v/v); flow, $1 \mathrm{ml} /$ minute; detection by Photodiode Array. One pure product was obtained from SF-6: (4) $[\mathrm{Rt}=13.62$ minutes; $15.7 \mathrm{mg}$.

\section{Physico-chemical Properties}

Circumdatin H (1) was obtained as a colorless amorphous substance. HREIMS $m / z \quad 347.1364\left(\mathrm{M}^{+}\right)$(calcd for $\left.\mathrm{C}_{20} \mathrm{H}_{17} \mathrm{~N}_{3} \mathrm{O}_{3}, 347.1269\right)$. UV (MeOH) $\lambda_{\max }(\log \varepsilon) 329$ (3.08), 276 (2.61), 230 (2.04) nm; IR (film) $v_{\max } 2929$, $1685,1644,1618,1495,1449,1367,1239 \mathrm{~cm}^{-1} \cdot[\alpha]_{\mathrm{D}}$ $-26.3^{\circ}$ (c 0.078, MeOH). ${ }^{1} \mathrm{H}\left(300 \mathrm{MHz}, \mathrm{CDCl}_{3}\right)$ and ${ }^{13} \mathrm{C}$ $\left(75 \mathrm{MHz} \mathrm{CDCl}_{3}\right)$ NMR data (see Table 1).

Compound $\mathbf{2}$ was identified as circumdatin $\mathrm{E}$ by 
Table $1{ }^{1} \mathrm{H}$ and ${ }^{13} \mathrm{C}$ NMR Data of circumdatin $\mathrm{H}\left(\mathrm{CDCl}_{3}\right.$, $300 \mathrm{MHz}$ and $75 \mathrm{MHz}$, respectively)

\begin{tabular}{|c|c|c|c|}
\hline & $\delta_{\mathrm{H}}\left(\mathrm{m}^{a}, \mathrm{~J}\right.$ in $\left.\mathrm{Hz}\right)$ & $\delta_{\mathrm{C}}$ & $\mathrm{HMBC}$ with $\mathrm{H}$ \\
\hline 2 & - & 165.1 & 8.00 \\
\hline 3 & - & 133.1 & $7.57,8.00$ \\
\hline 4 & $8.00(\mathrm{dd}, 7.2,1.1)$ & 130.3 & - \\
\hline 5 & $7.55(\mathrm{~m})$ & 129.0 & - \\
\hline 6 & $7.57(\mathrm{~m})$ & 131.1 & 8.00 \\
\hline 7 & $7.57(\mathrm{~m})$ & 128.8 & 7.55 \\
\hline 8 & - & 134.2 & - \\
\hline 10 & - & 162.5 & - \\
\hline 11 & - & 124.2 & 7.65 \\
\hline 12 & $7.68(d, 2.9)$ & 107.3 & - \\
\hline 13 & - & 159.0 & $7.65,3.93$ \\
\hline 14 & $7.38(\mathrm{dd}, 8.9,2.9)$ & 125.3 & 7.68 \\
\hline 15 & $7.65(d, 8.9)$ & 129.6 & - \\
\hline 16 & - & 141.7 & 7.38 \\
\hline 18 & - & 153.7 & $4.54,2.18$ \\
\hline 19 & $4.54(\mathrm{brd}, 7.5)$ & 59.2 & - \\
\hline $20 a$ & $3.16(\mathrm{~m})$ & 27.4 & - \\
\hline $20 b$ & $2.18(\mathrm{~m})$ & & \\
\hline $21 a$ & $2.32(\mathrm{~m})$ & 24.1 & 4.54 \\
\hline $21 b$ & $2.08(\mathrm{~m})$ & & \\
\hline $22 a$ & $3.62(\mathrm{~m})$ & 46.8 & - \\
\hline $22 b$ & $3.79(\mathrm{~m})$ & & \\
\hline 23 & 3.93 (s) & 56.3 & - \\
\hline
\end{tabular}

${ }^{a}$ multiplicity

comparison of its spectral data with the literature [8]. All data of compound 3 were coincident with flavacol $[10,11]$. Compound 4 was identified as stephacidin $\mathrm{A}$ by comparison of its spectral data with the literature [2].

\section{Biological Assays}

The inhibitory activity of alkaloids $\mathbf{1} \sim \mathbf{4}$ was assayed by using submitochondrial particles (SMP) from beef heart, according to Estornell et al. and Fato et al. $[14,15]$. Stock solutions ( $15 \mathrm{mM}$ in absolute EtOH) of $\mathbf{1} \sim \mathbf{4}$ were prepared and kept in the dark at $-20^{\circ} \mathrm{C}$. Each compound was added to the diluted SMP preparation and incubated, during 5 minutes, in ice. NADH oxidase activity was measured according to Fontana et al. [16]. For each compound, three experiments were carried out.

\section{Results and Discussion}

The isolation and structure characterization of a novel benzodiazepine, circumdatin $\mathrm{H}$ (1), as a minor constituent of A. ochraceus culture broth is reported, together the known benzodiazepine circumdatin E (2) [8], the pyrazinone flavacol (3) $[10,11]$ and the alkaloid stephacidin A (4) [2].

The structure of 1 was determined by comparison of its ${ }^{1} \mathrm{H}$ NMR and ${ }^{13} \mathrm{C}$ NMR spectral data (Table 1) with those of other known circumdatins, especially $\mathbf{2}$, and was confirmed by 2D NMR experiments (COSY H-H, HSQC and HMBC) $[7,9]$. According to the spectral data of $\mathbf{1}$, this compound presented a benzodiapezine structure derived from proline and anthranilic acid joined to another anthranilic acid unit, as in $\mathbf{2}$ and circumdatin $\mathrm{D}(\mathbf{5})$.

A molecular formula of $\mathrm{C}_{20} \mathrm{H}_{17} \mathrm{~N}_{3} \mathrm{O}_{3}$ for $\mathbf{1}$, determined by HREIMS, indicated that $\mathbf{1}$ had one less oxygen atom compared with 2. Examination of the ${ }^{1} \mathrm{H}, \mathrm{COSY}$ and HMBC spectra of $\mathbf{1}$ indicated the presence of three aromatic protons in ring $\mathrm{D}(\delta 7.68 \mathrm{~d}, J=2.9 \mathrm{~Hz} ; 7.65 \mathrm{~d}, J=$ $8.9 \mathrm{~Hz} ; 7.38 \mathrm{dd}, J=8.9,2.9 \mathrm{~Hz}$ ) in place of the two aromatic protons in $\mathrm{D}$ ring of $\mathbf{2}$. Also, $\mathbf{1}$ presented a $\mathrm{D}$ ring methoxy group at $\mathrm{C}-13$ as in 2, according to long-range ${ }^{1} \mathrm{H}-{ }^{13} \mathrm{C}$ correlations (from $\mathrm{C}-13$ to $-\mathrm{OCH}_{3}-23$ and $\mathrm{H}-15$; from $\mathrm{C}-16$ to $\mathrm{H}-14$; and from $\mathrm{C}-14$ to $\mathrm{H}-12$ ) observed in the HMBC spectrum of $\mathbf{1}$, and according to the NOE correlation between $-\mathrm{OCH}_{3}-23$ and $\mathrm{H}-12$. Thus, the only difference between $\mathbf{1}$ and $\mathbf{2}$ was the substitution of the D ring hydroxy group in $\mathbf{2}$ with a proton in $\mathbf{1}$. The stereochemistry at C-19 of 1 was tentatively assigned by comparison of the sign of the optical rotation value of $1\left(-26.3^{\circ}\right)$ with that of other circumdatins.

The structural resemblance of the quinazolinone moiety of these alkaloids with some moieties of the well-known inhibitors of the mitochondrial respiratory chain such as fenazaquin, prompted us to the evaluation of $\mathbf{1}$ and $\mathbf{2}$ as inhibitors of this process $[12,13]$. Alkaloids $\mathbf{1}$ and $\mathbf{2}$ were found to be inhibitors of the integrated electron transfer chain (NADH oxidase activity) with $\mathrm{IC}_{50}$ values of $1.5 \pm 0.1$ and $2.5 \pm 0.3 \mu \mathrm{M}$, respectively. Alkaloids 1 and 2 were placed in a middle range with respect to the most potent complex I respiratory inhibitors, such as rotenone, with an $\mathrm{IC}_{50}$ of $4.4 \mathrm{nM}$ [17]. Alkaloid 1 was more slightly active than 2 ; therefore it seems possible that the hydroxy group at C-15 of 2 makes the interaction with the respiratory chain more difficult.

Flavacol (3) and stephacidin A (4) also were assayed as mitochondrial respiratory inhibitors, because they present a relative structural similarity with other known inhibitors such as rotenone or fenazaquin $[12,13]$. Compounds 3 and 4 were able to inhibit this respiratory chain with $\mathrm{IC}_{50}$ values between five and twenty-five times higher than $\mathbf{1}$ and $\mathbf{2}$ (Table 2). The slight inhibitory potency of $\mathbf{4}$ could demonstrate that the mitochondrial chain inhibition is not 
Table 2 Inhibitory potency of compounds $\mathbf{1} \sim \mathbf{4}$ against $\mathrm{NADH}$ oxidase

\begin{tabular}{cr}
\hline Inhibitors & $\mathrm{IC}_{50}(\mu \mathrm{M})$ \\
\hline $\mathbf{1}$ & $1.5 \pm 0.1$ \\
$\mathbf{2}$ & $2.5 \pm 0.3$ \\
$\mathbf{3}$ & $13.0 \pm 0.4$ \\
$\mathbf{4}$ & $34.6 \pm 2.2$ \\
\hline
\end{tabular}

the mechanism of action that explains the antitumor activity of this compound $[2,3]$.

Circumdatins show a range of inhibitory activity similar to other interesting inhibitors of the mammalian mitochondrial respiratory chain, such as stolonoxides [16]. As other inhibitors of the complex I respiratory chain, the more active compounds $\mathbf{1}$ and $\mathbf{2}$ may serve as leads for the development of news tools for insect control based in this mechanism of action and also for basic biomedical research $[12,13,17,18]$. Thus, detailed comparisons of the inhibitory action of structurally different inhibitors will lead to better understanding of the mechanism of redoxdriven proton pumping in the mitochondrial respiratory chain, whose defects are associated with degenerative diseases such as Parkinson's and Huntington's diseases [18].

Acknowledgments The authors acknowledge the Consejería de Educación y Ciencia de la C. Valenciana, for the doctoral grant to M. P. L. The Comisión Interministerial de Ciencia y Tecnología (CICYT), Consejería de Agricultura, P. y A. de la C. Valenciana and FEDER-FSE of the European Union, for the financial support. The authors thank Dr. Letizia Ciavatta for recording the 600-MHz NMR spectra.

\section{References}

1. Fenical W, Jensel PR, Cheng XC. Avrainvillamide, a Cytotoxic Marine Natural Product, and the Derivatives. U.S. 6,066,635, May 23 (2000)

2. Cutrone JQ, Krampitz KD, Shu YZ, Chang LP, Lowe SE. Stephacidin antitumor antibiotics. U.S. 6,291,461, September 18 (2001)

3. Cutrone JQ, Huang S, Shu YZ, Vyas D, Fairchild C, Menéndez A, Krampitz K, Dalterio R, Klohr SE, Gao Q. Stephacidin A and B: Two structurally novel, selective inhibitors of the testosterone-dependent prostate LNCaP cells. J Am Chem Soc 124: 14556-14557 (2002)
4. Schwartz RE, Onisi JC, Monaghan RL, Liesch JR, Hensens OD. Production of antifungal pyrrolidine antibiotics by Aspergillus ochraceus. U.S. 4,847,284, July 11 (1989)

5. Balcells M, Canela R, Coll J, Sanchis V, Torres M. Effect of fungal metabolites and some derivatives against Triboleum castaneum (Herbst) and Nezara viridula (L.). Pestic Sci 45: 319-323 (1995)

6. Sugie Y, Hirai H, Inagaki T, Ishiguro M, Kim YJ, Kojima Y, Sakakibara T, Sakemi S, Sugiura A, Suzuki Y, Brennan L, Duignan J, Huang LH, Sutcliffe J, Kojima N. A new antibiotic CJ-17,665 from Aspergillus ochraceus. J Antibiot 54: 911-916 (2001)

7. Rahbak L, Breinholt J, Frisvad JC, Christophersen C. Circumdatin A, B, and C: Three new benzodiazepine alkaloids isolated from a culture of the fungus Aspergillus ochraceus. J Org Chem 64: 1689-1692 (1999)

8. Rahbak L, Breinholt J. Circumdatins D, E, and F: Further fungal benzodiazepine analogues from Aspergillus ochraceus. J Nat Prod 62: 904-905 (1999)

9. Dai JR, Carte BK, Sidebottom PJ, Yew ALS, Ng SB, Huang Y, Butler MS. Circumdatin G, a new alkaloid from the fungus Aspergillus ochraceus. J Nat Prod 64: 125-126 (2001)

10. Yamazaki M, Maebayashi Y, Miyaki K. Isolation of a new type of pyrazine metabolite from Aspergillus ochraceus Wilh. Chem Pharm Bull 20: 2274-2276 (1972)

11. MacDonald JC, Bishop GG, Mazurek M. ${ }^{13} \mathrm{C}$ and proton MNR spectra of 2(1H)pyrazinones. Tetrahedron 32: 655-660 (1976)

12. Lümmen P. Complex I inhibitors as insecticides and acaricides. Biochim Biophys Acta 1364: 287-296 (1998)

13. Miyoshi H. Structure-activity relationships of some complex I inhibitors. Biochim Biophys Acta 1364: 236-244 (1998)

14. Estornell E, Fato R, Palloti F, Lenaz G. Assay conditions for the mitochondrial NADH: coenzyme Q oxidoreductase. FEBS Lett 332: 127-131 (1993)

15. Fato R, Estornell D, Bernardo S, Palloti F, Parenti-Castelli G, Lenaz G. Steady-state kinetics of the reduction of coenzyme Q analogs by complex I (NADH: Ubiquinone oxidoreductase) in bovine heart mitochondria and submitochondrial particles. Biochemistry 35: 2705-2716 (1996)

16. Fontana A, Cimino G, Gavagnin M, González MC, Estornell E. Novel inhibitors of mitochondrial respiratory chain: Endoperoxides from the marine tunicate Stolonica socialis. J Med Chem 44: 2362-2365 (2001)

17. Fang N, Casida JE. Cubé resin insecticide: Identification and biological activity of 29 rotenoid constituents. J Agric Food Chem 47: 2130-2136 (1999)

18. Weiss H, Friedrich T, Hofhaus G, Preis D. The respiratorychain NADH dehydrogenase (complex I) of mitochondria. Eur J Biochem 197: 563-576 (1991) 